\title{
SURVEYING DESIGN SKILL DEVELOPMENT IN WORK- INTEGRATED LEARNING EXPERIENCES: A REVIEW OF THE LITERATURE
}

\author{
Litster, Gregory; \\ Hurst, Ada; \\ Pretti, T. Judene \\ University of Waterloo
}

\begin{abstract}
Work-integrated learning (WIL) is an educational approach that intentionally scaffolds work experiences throughout undergraduate education. This approach has been proven to provide many benefits to students, including increased grade point averages, better job prospects after graduation and skill development. As such, we expect WIL experiences to contribute to engineering student's ability to design, a central aspect of both engineering education and practice. We found little evidence of research related to WIL experiences in the design literature, so we conducted a secondary data analysis on 33 publications from engineering education literature focusing on student WIL experiences with design. The review found evidence of students using a design process and recognizing the importance of designing within context, focusing on health, safety and ethical concerns of being an engineering designer. However, there was little evidence found of what students actually designed (i.e., components, systems or processes). We highlight some interesting areas for future research, specifically for design researchers to investigate how student work experiences are contributing to their development of design knowledge, skills and abilities.
\end{abstract}

Keywords: Design education, Design learning, Design practice, work-integrated learning, literature review

Contact:

Litster, Gregory

University of Waterloo

Management Sciences

Canada

gmlitste@uwaterloo.ca

Cite this article: Litster, G., Hurst, A., Pretti, T. J. (2021) 'Surveying Design Skill Development in Work-Integrated Learning Experiences: A Review of the Literature', in Proceedings of the International Conference on Engineering Design (ICED21), Gothenburg, Sweden, 16-20 August 2021. DOI:10.1017/pds.2021.546 


\section{INTRODUCTION}

Opportunities for work-integrated learning (WIL), an educational approach that uses relevant workbased experiences as an intentional part of the curriculum, are becoming increasingly popular in universities and other higher education institutions around the world (International Journal of WorkIntegrated Learning, n.d.). WIL has been accepted as a highly effective method to support graduates moving from higher education to the workplace (Khampirat et al., 2019). Since its initial implementation at the University of Cincinnati in 1906, WIL has become a key component of many engineering programs (Blair et al., 2004).

As design is central to engineering education and practice, we expect that WIL experiences contribute to the development of the design knowledge, skills, and abilities (KSAs) of engineering graduates. However, while there is a considerable amount of research on student learning during WIL experiences (Blicblau et al., 2016; Jackson, 2015; Little and Harvey, 2006) there is little targeted emphasis placed on learning of design KSAs. As such, the broader motivation for this work is to understand the contribution WIL experiences are making towards developing design skills in undergraduate engineering students. In this paper, we conduct a review of the literature to identify design competencies students are gaining in WIL experiences, with the goal of motivating future targeted studies of students' design learning in these settings and the challenges and opportunities in integrating that learning into the design curriculum.

The remainder of the paper is structured as follows: in section 2 we introduce and review WIL more generally, including some of the benefits it provides and the various implementations of the approach. In section 3 we explain the methodology and dataset we used for this analysis. We describe the findings of our analysis in section 4 and discuss the limitations of our approach in section 5 . This is followed by conclusions and future directions in section 6 .

\section{WORK INTEGRATED LEARNING}

By definition, WIL programs include a partnership between an academic institution, a host organization or employer, and a student (Co-operative Education and Work-Integrated Learning Canada, n.d.). One of the desired outcomes for using a framework of WIL in higher education is to better prepare students for entry into the workforce (Jackson, 2015). Students are exposed to authentic work practices, where collaborative social interaction with workplace professionals and reflection on those experiences becomes the foundation for student learning (Von Treuer et al., 2011). Experiential learning is achieved when the cycle of experience, reflection and learning is completed (Kolb, 1984).

A growing body of literature advocating for a WIL approach reports on three areas of student learning - academic, personal, and professional - which all contribute to the success of preparing work ready graduates. Investigations of academic performance for those students who participate in WIL compared to those that do not, report significant differences between these two groups. For example, a study found that compared to students who participated in a WIL experience, non-WIL students had lower grade point averages, used more shallow learning strategies, and were more extrinsically motivated academically (e.g., achieving high grades, seeking approval from external sources), which is found to be correlated with poorer learning and academic outcomes (Drysdale and McBeath, 2018). In a similar study of engineering students, Blair et al. (2004) report that students who participated in three WIL experiences had higher averages than their non-WIL peers. According to student selfreports, specific academic skills (problem solving, critical thinking, communication and teamwork) increase after participation in a work placement (Rampersad and Zivotic-Kukolj, 2018).

In addition to the academic benefits of WIL experiences, students who participate in WIL programs also gain other practical and personal benefits. A Canadian study found that the percentage of students who accumulate debt during their undergraduate education is less for those who participate in a WIL program, indicating an increased ability for students to finance their own education (Haddara and Skanes, 2007). WIL experiences seem to be an ideal space to develop professional identity, as students are able to practice learning professional roles, begin to understand workplace cultures, and socialize in appropriate discipline-specific communities of practice (Trede, 2012). The inclusion of WIL programs allows students to practice these skills, which often results in students returning to university with an attitude of being a young professional, rather than a student (Howard, 2009). More practically, students who participate in WIL experiences have been observed to begin their careers with higher 
starting salaries and the initial salary gap between these two groups continues to persist well beyond graduation (Finnie and Miyairi, 2017).

There are different implementations of WIL experiences, with the most significant differences related to structure. Examples of WIL experiences include applied research projects, apprenticeships, cooperative education, entrepreneurships, field placements, internships, professional practicum/clinical placements, and service learning (Co-operative Education and Work-Integrated Learning Canada, n.d.). Apprenticeships are usually longer in length, but are similar to field placements, where students work directly with a professional in the relevant field to gain experience. Co-operative education typically takes one of two formats: co-op alternating or co-op internships (sometimes called sandwich placements). Both models have students working with a company for a period of time, working under a supervisor as either a paid or unpaid worker. The difference between the two is usually the duration and frequency of work experience, with co-op alternating having more frequent, short term work experiences compared to the co-op internship model. The difference between these experiences and any other work students may complete during their studies (i.e. part-time or summer employment) is the relevance of the job in relation to the student's academic discipline.

In order to explore the efficacy of WIL experiences, we must be able to measure student learning at work. Fenwick (2000) reviews five theoretical frameworks that can be used to assess student learning in relation to work experiences. Two of these, reflective learning theory and participation learning theory, are relevant to this discussion. The influential reflective learning theory (Schon, 1983) proposes that the learner reflects on lived experience and is able to interpret and generalize from these experiences, creating the foundation for learning. Similarly, Lave and Wenger's (1991) participation learning theory is rooted in the belief that learning depends on the community, tools and activity of the situation. Knowledge is able to emerge as a result of these elements interacting.

\section{AIMS}

Despite the long history of WIL and its presence and impact in engineering education, to our surprise design learning during WIL experiences has not received significant attention from the design research community. Notably, at the time of writing of this paper, a search of WIL-related keywords in the Design Studies journal produced zero results. We wish to develop an understanding of how WIL experiences are contributing to the development of students design competencies. Using the two frameworks briefly reviewed above as a theoretical foundation, in this paper we survey the literature to understand how students' WIL experiences and their reflections contribute to their design learning.

\section{METHODOLOGY}

We first conducted a number of semi-structured literature searches, seeking to explore the intersections of three bodies of literature: design research, engineering education, and WIL. We were not successful in producing a search protocol that would produce a suitable number of records - our searches producing either too few or too many (i.e., thousands) results. We conducted a few more unstructured searches in other journals and discovered a literature review by Liu et al. (2020), which aimed to identify workplace affordances and individual engagement from work experience. The details of the selection process used by Lui et al. (2020) can be found in the original article, but a brief summary is provided here. The articles were curated from the Journal of Engineering Education (JEE), the European Journal of Engineering Education (EJEE), and from the American Society of Engineering Education (ASEE) conference proceedings. Searches were also conducted in a major education data base, ERIC, and a major engineering database, Compendex. The keywords or phrases "work-integrated learning", "workplace learning", co-op, internship, and "cooperative education" were used in various combinations at different levels of paper structure (i.e., abstract, title, entire document). Additional snowballing using the reference lists of the ASEE conference proceedings and the ERIC database articles was also completed. The 30 records that were eventually included in their review were empirical studies of undergraduate engineering students' in-person co-op or internship experiences in the workplace published after 1990. Although it was entirely possible for us to complete the literature search and article scans ourselves, we felt that the description of Lui et al.'s (2020) methods and inclusion criteria were adequate to justify using the articles for our investigation. In addition to the 30 publications sourced from that review, we have also included 3 additional publications found through our own searches that we felt matched the inclusion criteria and provided 
insight into the design learning of students during a WIL experience. The articles from Liu et al., (2020) and those added to the analysis that are referenced in this paper are highlighted with an asterisk $\left(^{*}\right)$ in the reference list.

The scope of our analysis of the 33 publications was the identification of design KSA's students might develop during WIL experiences. We analysed these papers using a particular lens of design, which is derived from the definition used by the Canadian Engineering Accreditation Board (CEAB) in the 2019 Accreditation Criteria and Procedures (p. 13). The CEAB definition of design has three distinct characteristics. The first is the emphasis on the development of "elements, systems and processes" to meet specific needs. The second is the activity of designing itself, which necessitates the use of a "creative, iterative and open-ended" design process. The final element relates to how the first two components fit into a larger context, including the impact of engineering design on society and the environment, taking special interest in the safety and ethical considerations of designing. The first author scanned each of the 33 publications included in this review for evidence of one or more of these three aspects of design. The purpose and lens of our analysis is significantly different from that employed by Lui et al. (2020); therefore, we do not believe that there is significant overlap in our findings and discussion.

\section{RESULTS}

Our review found varying degrees of evidence related to the three aspects of design described above. Students were found to have developed elements (Smith and Lucena, 2016; Peters and Arbor, 2014), used and referenced different stages of the design process (Pierrakos et al., 2008), and had a significant understanding of designing in a larger social context (Rulifson and Bielefeldt, 2018). In addition to those skills related to design specifically, we also found evidence of skill development outside of this definition of design that might still contribute to the development of competent engineers. The following sub-sections provide a detailed account of the found evidence of student design learning during WIL experiences.

\subsection{Design of components, systems and processes}

The review included only two records of students describing or reporting an experience of designing an element, system, or process in a WIL setting. The first, reported by Smith and Lucena (2016), had one student participant, "Brian", who worked on remodelling a natural gas regulator station. The student encountered a situation where ball valves needed constant replacement, which he later investigated more in depth. In this publication we see direct evidence of the student engaging in the design of an element. The second record is the study by Peters and Arbor (2014), where a student was quoted saying that they "had to design quite a few tool organizers and shelf units for specific places" (pg. 6).

Although there was little concrete evidence of what artefacts students designed in their WIL experiences, many of the reviewed publications reported evidence of students applying engineering knowledge during their WIL experiences. These were typically reported as measurements of ABET (United States equivalent of CEAB) criteria. In an investigation of the ABET learning outcomes of engineering students, Parsons et al. (2005) found that students' mean rating of the ABET criteria "design of a system, component or process to meet a desired need" and "application of knowledge of mathematics, science and engineering" during a WIL experience indicated at least some learning by the students. In a survey study, Yin (2010) reports that WIL graduates had adequate or more than adequate ability to ensure that a process or product meets technical and practical criteria.

Nagel et al. (2012) conducted a similar study related to the structuredness and complexity of industry experiences, in which they found that $70 \%$ of students who participated in their study rank their ability to apply engineering design skills, including computational, numerical, and experimental tools, as having developed significantly from their industry experiences. Likewise, results from Pierrakos et al. (2008) highlight that students' ability to apply scientific and engineering knowledge is very high, with $89.5 \%$ of respondents ranking the ability with a 4 or 5 (on a 5-point Likert scale). In that case, student ratings of the application of this knowledge were related to their ability to analyse the performance of a process or system. In an investigation of the differences of learning experiences between male and female engineering students, Anderson et al. (2011) found that $61 \%$ of their participants reported applying knowledge during their co-ops. Interestingly, male respondents of this survey were more likely (though not at a statistically significant level) to discuss the application of knowledge during a 
WIL experience in their responses to open ended survey questions compared to females. Dansberry (2012) found that a significant portion of participants of a NASA engineering internship, based on their responses to an exit survey, reported growth in the ability to apply knowledge. Similarly, Chen et al. (2018) identified that students' co-op experiences increased in engineering task self-efficacy. This resulted in an increased confidence when analysing the operation or functional performance of a complete system.

We note again that despite the presented evidence of students applying engineering knowledge in their WIL experiences, only two of the reviewed publications describe what elements, systems or processes were being designed. One potential reason for this is related to the limitation of our secondary data analysis approach, as these records were not originally selected for the purpose of identifying design artifacts, which might indicate why descriptions of the designs are limited. However, based also on the difficulty in extracting such examples in our own independent searches, we suspect that another likely reason is that the activity of designing in WIL experiences has not yet invited much research attention.

\subsection{Use of design methods}

Although there are many different models of the design process, a typical model will include aspects of identifying a need, defining and analysing the problem, prototyping and building, making critical decisions, and communicating those decisions in a way that is useful (Daly et al., 2012). The reviewed publications presented substantial evidence of students participating in at least one aspect of this process during their WIL experiences. One of the most general examples of students using process was found in Rowe and Mulroy (2004), which included one quote from a student who learned "how projects are run" (pg. 5). In the survey study by Yin (2010), 90\% of student respondents felt they had adequate ability to identify critical variables and information, develop a course of action based on their understanding of those variables, compare and judge alternatives, and ultimately draw conclusions from evidence. It should be noted that when a multi-nominal logit model was used to determine the if the time spent during a co-op or internship experience would affect these competencies, only two competencies - the ability to develop a course of action and compare and judge alternatives - were statistically significant (Yin, 2010). In this study, it is evident that students are using design methods during their internships.

In an interview study of interns, half were testing or building upon previously created models - an important part of a design process (Chen et al., 2018). However, those same students also reported not necessarily requiring an approach of creativity because they were building something off a previous model. In Pierrrakos et al. (2008), when students were asked to rate the learning outcomes of a WIL experience on a Likert scale form 1-5, it was found that students self-identified (with a rank of 4 or 5) with the ability to identify and establish design requirements and constraints (86.4\%), formulate a range of solutions to their engineering problems (91.4\%), and were able to use evidence to draw conclusions or make recommendations $(94.8 \%)$. Bailey (2007) focusses explicitly on the effect of industrial experience in relation to student design learning and finds that senior students with industrial experience were able to understand, in more detail, the importance of documentation throughout the design process compared to those students who did not have industrial experience. In another study by Powers et al. (2018), which explored the influence an internship or research experience might have on student career decisions, one student commented that learning how to build models using software in the workplace was an important part of their experience. Similarly, in Smith and Lucena (2016) the same participant highlighted earlier, "Brian", noted that as part of his process he would engage with the operators of equipment he was designing and ask for feedback. In this case, it is obvious that Brian was using an iterative design process.

Finally, an important part of the engineering design process is the ability to conduct design research for your product. One participant in a study by Fisher (2017) reported that "design research is essential when the designers are not the users" (pg. 11) indicating an increased understanding, and possible use, of user research.

\subsection{Designing within a larger social context}

The move towards encouraging young designers to recognize the larger social context in which they design, stems from the increasing difficulty associated with the environmental, social, political, and ethical situations we face (Titus and Oakes, 2011). The reviewed publications showed promising 
evidence that students participating in WIL experiences are developing a deep understanding of what it means to design in a larger social context. For example, in Nagel et al. (2012), more than $70 \%$ of the respondents reported more than an adequate ability or high ability to understand the global and societal impact of engineering solutions. A similar result was found in Pierrakos et al. (2008), where around $70 \%$ of respondents indicated an understanding of the societal and global impact of engineering solutions (although it was found to be among the fifteen lowest ranked outcomes).

A study by Dehing et al. (2013) on teaching staff perspectives of students' co-op learning experiences, showcases the role industry plays in developing students' engineering identity because of the authentic engineering challenges it forces students to face. Similarly, in a study by Kovalchuk et al. (2017), which focused on understanding the transition of recent graduates who had work experience as undergraduates into industry, one student reported that her internship exposed her to complex, realworld problems that she did not experience at university. She went on to say "When you get out in the real world, you don't have a simple frame. It is never simple" (p. 5). One participant quoted in Smith and Lucena's (2016) study identifies the importance of designing in context: "[A]s an engineer I would design not only for the job but for how the job affects the [user]...If I am designing a piece of frack blender, I would put myself in the mechanics shoes" (p. 17).

Gordon et al. (2017) reported on students' ability to make a difference from their engineering work. They note that students who participated in an international service-oriented internship identify that the extent to which their ability to change the world and local community was greater than the selfidentified ability of those students who did not complete an internship. This leads us to believe that students who participate in an internship are more likely to understand the impact of engineering design work. Tillman (1990) investigated the ethical orientation of civil engineering students after their co-op experiences and found that those students do consider the consequences of their ethical decisions to be important. Specifically, of three core ethical concepts, students identified that their actions are most important in relation to matters of public welfare (Tillman, 1990). In Renganathan et al. (2012), they found that over $80 \%$ of their respondents were able to learn and appreciate the social and ethical responsibility during their internships.

Another study by Rowe and Mulroy (2004), found students reported increased knowledge in finance, rules and safety aspects of being an engineer because "there are so many different things you have to know". Rulifson and Bielefeldt (2018), who investigated the effect of internships on engineering students' definition or understanding of socially responsible design, found evidence of three different effects of internships on students' understanding of socially responsible engineering: minimally impacted, narrowed, or expanded. While the majority of the students did not express a significant difference in their understanding of socially responsible engineering, and three students even reported that internship experience narrowed their understanding of responsibility, one student is quoted saying "I would like to be in a position where I feel like I am making a difference...that helps the larger population" (p. 4). This same student was also able to describe the responsibilities she would have as an engineer in the future, such as safety of users, convenience for the public and client demands. Although this study found evidence of the internship experience not changing or narrowing student's ability to understand the larger context of engineering practice, it is promising to see that for some students there was some appreciation of context.

\subsection{Other competencies gained}

The focus of our review of these publications was to understand what specific design knowledge (in terms of artifact, process and context) was gained during students' WIL experiences. However, there are also other competencies found throughout these publications which are not explicitly related to design but would contribute to a student's overall experience of becoming a competent engineering designer. For example, one of the most consistent findings among the papers was the development of professional identity or understanding of what engineers do (Dehing et al., 2013a; Dehing et al., 2013b; Eliot and Turns, 2011; Renganathan et al. 2012). This was also echoed by an increase in confidence working as a professional for those who participated in internships (Rowe and Mulroy, 2004). On a related topic, some students identified an increase in leadership or managerial capabilities because of their WIL experiences (Renganathan et al., 2012). Another significant gain that was observed in many of the studies was related to communication skills (Kovalchuk et al., 2017; Powers et al., 2018). This can be related to technical communication (Dansberry, 2012), writing both individually and, less so, collaboratively (Kreth, 2000), and finally oral communication (Renganathan 
et al., 2012). In some of the reviewed studies, students also reported an increase ability to manage their time (Anderson et al., 2011; Jaime et al., 2020; Kovalchuk et al., 2017) and organize/plan for themselves (Dansberry, 2012). As we can see, it is evident that WIL experiences are valuable, but as noted in Filfolt and Searby (2010), it is important to provide quality work experiences that are planned, substantial and occurring in real settings for them to be most effective.

\section{LIMITATIONS}

As with any work, there are limitations to the findings we have presented here. The first is related to the nature of secondary data analysis. Walther et al. (2013) emphasize that the quality of research is dependent on both the "making" and "handling" of data. In the case of this paper, we were not responsible for the "making" of the data, that is, the selection process of articles apart from the 3 articles we added. The inclusion criteria provided in the original report by Liu et al. (2020) is beneficial for reproducibility, but we were not responsible for the selection of articles. We recognize that if we had conducted the search ourselves it is likely that a different set of articles would have been selected and thus any evidence we would have presented in this article would be subject to those differences.

A second limitation we notice in our findings is that all evidence provided here is subject to the limitations identified in each of the studies. For example, Bailey (2007) notes that part of their data was based on students' perception of their experiences that involved design. In this case, students do not all share the same idea of what design is and so any conclusions they draw about design might be different. A final limitation is related to timelines in which the studies were conducted. As noted in Rulifson and Bielefeldt (2018), actual data collection, whether it is in the form of a survey or interview, can occur many months after students take part in a WIL experience and so the impact of those experiences might have faded.

\section{CONCLUSION AND FUTURE DIRECTIONS}

Our primary goal was to identify what evidence exists of design learning during WIL experiences of undergraduate engineering students. In this paper we have reviewed 33 articles (including a dataset of 30 articles originally created by Liu et al. (2020) for a different analysis) to identify themes of design learning in engineering students WIL experiences. We found some (limited) evidence of students designing elements, systems, or processes using an engineering design process. We can also highlight the fact that students are recognizing the importance of designing in a larger context, especially in regard to health, safety and ethical considerations.

The results of this review are promising and lead to interesting new directions for future research. It is important to acknowledge that both the WIL (Fleming and Zegwaard, 2018) and design (Cash et al., 2013) research literature place a strong emphasis on using diverse methodological approaches. As such, a collaborative approach between these two disciplines is necessary for future investigations of WIL experience and design (education).

Investigations of students' design learning in WIL experiences is particularly relevant for informing design pedagogy for when those students return to the classroom. One example of this integration can be found in Nespoli and Lambert (2010), where work reports of students' co-op experiences were used to generate case studies to teach design in a graduate course. Similarly, Nespoli et al. (2018) report a case study of students receiving remote instruction on need finding and problem formulation while immersed in design practice during a co-op term. The students were then expected to bring authentic design problems into the classroom in the capstone course immediately following the cooperative term. The influence WIL experiences have on the capstone design course, as briefly described in Bailey (2007), are particularly relevant. A future study could follow a team of students during their capstone design project to observe how their individual WIL experiences influence their group processes. Specifically, one might try to determine how these experiences influence negotiations between team member preferences for design tools, processes and approaches that they learned during a WIL experience, or constraints posed by the instructor of the course on design processes and deliverables.

In conclusion, we believe that a more in-depth exploration of student design learning during WIL experiences is valuable in our pursuit of effectively educating engineer undergraduates to tackle the complex problems we face moving forward. We call for the intersection of design, engineering education, and WIL disciplines to come into research focus, believing this to be an important factor that can improve design teaching practices in the future. 


\section{REFERENCES}

*Anderson, K. J., Prem, K. J. and Courter, S. S. (2011), "Comparing the Learning Experiences of Male and Female Engineering Students in Internship and Co-operative Educational Opportunities.” Proceedings of the ASEE Annual Conference and Exposition, Vancouver.

*Bailey, R. (2007), "Effects of Industrial Experience and Coursework During Sophomore and Junior Years on Student Learning of Engineering Design”, Journal of Mechanical Design, Vol. 129, pp. 662-667.

Blair, B., Millea, M. and Hammer, J. (2004), "The Impact of Cooperative Education on Academic Performance and Compensation of Engineering Majors", Journal of Engineering Education, pp. 333-339.

Blicblau, A. S., Nelson, T. L. and Dini, K. (2016), “The role of work placement in engineering students academic performance." Asia-Pacific Journal of Cooperative Education, Vol. 17, No. 1, pp. 31-43.

Canadian Engineering Accredidation Board, (2019), “2019 Accreditation Criteria and Procedures”, Ottawa: s.n. Accessed from https://engineerscanada.ca/sites/default/files/2021-03/Accreditation-Criteria-Procedures2019.pdf

Cash, P. J., Hicks, B. J. and Culley, S. J. (2013), “A comparison of designer activity using core design situations in the laboratory and practice", Design Studies, Vol. 34, No. 5, pp. 575-611.

*Chen, H. L., Powers, K., Prasad, K. V., Anderson, M., Royalty, A., Gilmartin, S. K., and Sheppard, S. D. (2018), "A mixed methods approach to understanding how colleges, universities, and employers prepare and support undergraduates in engineering internships", Proceedings of the IEEE Frontiers in Education Conference (FIE).

Co-operative Education and Work-Integrated Learning Canada, n.d. "What is WIL?" [Online]

Available at: https://www.cewilcanada.ca/What_is_WIL_.html [Accessed 18 November 2020].

Daly, S. R., Adams, R. S. and Bodner, G. M. (2012), "What Does it Mean to Design? A Qualitative Investigation of Design Professionals’ Experiences”, Journal of Engineering Education, Vol. 101, No. 2, pp. 187-219.

*Dansberry, B. E. (2012), "Examining outcomes data from an undergraduate internship program", Proceedings of the ASEE Annual Conference and Exposition, San Antonio.

*Dehing, A., Jochems, W. and L., B. (2013b), "The Development of Engineering Students Professional Identity During Workplace Learning in Industry: A study in Dutch Bachelor Education", Engineering Education, Vol. 8, No. 1, pp. 42-64.

*Dehing, F., Jochems, W. and Baartman, L. (2013a), "Development of an engineering identity in the engineering curriculum in Dutch higher education: an exploratory study from the teaching staff perspective", European Journal of Engineering Education, Vol. 38, No. 1, pp. 1-10.

Drysdale, M. T. B. and McBeath, M. (2018), "Motivation, self-efficacy and learning strategies of university students participating in work-integrated learning", Journal of Education and Work, Vol. 31 No. 5-6, pp. 478-488.

*Eliot, M. and Turns, J. (2011), "Constructing Professional Portfolios: Sense-Making and Professional Identity Development for Engineering Undergraduates”, Journal of Engineering Education, Vol. 100, No. 4, pp. 630-654.

Engineers Canada, (2019), “The Engineering Design Task Force Report”. Ottawa, s.n.

Fenwick, T. J. (2000), "Expanding Conceptions of Experiential Learning: A review of the five contemporary perspectives on cognition", Adult Education Quarterly, Vol. 50, No. 4, pp. 243-272.

Finnie, R. and Miyairi, M. (2017), "The Earnings Outcomes of Post-secondary Co-op Graduates: Evidence from Tax-linked Administrative Data”, Ottawa: Education Policy Research Initiative.

*Fisher, E. (2017). "Sharing Student Learning from Individual Internship Experiences", Proceedings of the ASEE Annual Conference and Exposition, Columbus.

Fleming, J. and Zegwaard, K. E. (2018), "Methodologies, methods and ethical considerations for conducting research in work-integrated learning", International Journal of Work-Integrated Learning, Special Issue, Vol. 19, No. 3, pp. 205-213.

*Gordon, A. S., Plumblee II, J. M. and Dancz, C. L. (2017), "Developing Leadership through an Immersive Service-Oriented International Internship". Proceedings of the ASEE Annual Conference and Exposition, Pittsburgh.

Haddara, M. and Skanes, H. (2007), “A reflection on cooperative education: from experience to experiential learning", Asia-Pacific Journal of Cooperative Education, Vol. 8, No. 1, pp. 67-76.

Howard, P. (2009), “Articulating the learning: professional practice made explicit”, Asia-Pacific Journal of Cooperative Education, Vol. 10, No. 3, pp. 177-188.

International Journal of Work-Integrated Learning, n.d. "Defining Work-Integrated Learning", [Online] Available at: https://www.ijwil.org/defining-wil [Accessed 1610 2020].

Jackson, D., (2015), "Employability skill development in work-integrated learning: Barriers and best practice", Studies in Higher Education, Vol. 40, No. 2, pp. 350-367.

*Jaime, A., Olarte, J. J. and García-Izquierdo, F. (2020), “The effect of internships on Computer Science Engineering Capstone Projects”, IEEE Transactions on Education, Vol. 63, No. 1, pp. 24-31. 
Khampirat, B., Pop, C. and Bandaranaike, S. (2019), "The effectiveness of work-integrated learning in developing student work skills: A case study of Thailand", International Journal of Work-Integrated Learning, Vol. 20, No. 2, pp. 127-146.

Kolb, D. A., (1984), "Experiential learning: experience as the source of learning and development”. Englewood Cliffs, NJ: Prentice Hall.

*Kovalchuk, S., Ghali, M., Klassen, M., Reeve, D. and Stacks, R. (2017), “Transitioning from University to Employment in Engineering: The Role of Curricular and Co-Curricular Activities”, Proceedings of the ASEE Annual Conference and Exposition, Columbus.

*Kreth, M. L. (2000), “A Survey of the Co-op Writing Experiences of Recent Engineering Graduates”, IEEE Transactions on Professional Communication, Vol. 43, No. 2, pp. 137-152.

Lave, J. and Wenger, E. (1991) "Situated learning: Legitimate peripheral participation. Cambridge University Press, New York.

Little, B. and Harvey, L. (2006), "Learning through work placements and beyond", A report for HECSU and the Higher Education Academy's Work Placements Organisation Forum.

Liu, Q., Reeve, D., Rottmann, C. and E., M. (2020), "Examining Workplace Affordance and Student Engagement in Engineering Co-op and Internship Literature", Canadian Journal of Science, Mathematics and Technology Education, Vol. 20, No. 1, pp. 116-129.

Nagel, J. K., Pierrakos, O., Zilberberg, A. and McVay, S., (2012), “Understanding industry experiences: From Problem Solving to Engineering Students Learning Gains", Frontiers in Education (FIE) Conference, Seattle.

Nespoli, O., Hurst, A. and Russel, J. (2018), "Facilitating need finding and problem formulation during cooperative workterms through virtual instruction - Pilot implementation results", DS92: Proceedings of the DESGIN 2018 15th International Design Conference, Design Society.

Nespoli, O. and Lambert, S. (2010), "Engineering design case studies: effective and sustainable development methods", Proceedings of the ASEE Annual Conference and Exposition, Louisville.

*Parsons, C. K., Caylor, E. and Simmons, H. S. (2005), "Cooperative Education Work Assignments: The Role of Organizational and Individual Factors in Enhancing ABET competencies and Co-op Workplace WellBeing”, Journal of Engineering Education, Vol. 94, No. 3, pp. 309-318.

*Peters, D. L. and Arbor, J. (2014), "Student Perceptions of Connections between Statics Class and Co-op Work Experience", Proceedings of the ASEE Annual Conference and Exposition, Indianapolis.

*Pierrakos, O., Borrego, M. and Lo, J. (2008), "Preliminary Findings from a Quantitative Study: What Are Students Learning During Cooperative Education Experiences?”, Proceedings of the ASEE Annual Conference and Exposition, Pittsburgh.

*Powers, K., Prasad, K. V. and Sheppard, S. (2018), "Exploring How Engineering Internships and Undergraduate Research Experiences Inform and Influence College Students' Career Decisions and Future Plans", Proceedings of the ASEE Annual Conference and Exposition, Salt Lake City.

Rampersad, G. and Zivotic-Kukolj, V. (2018), "Work-integrated learning in science, technology, engineering and mathematics: Drivers of innovation for students", International Journal of Work-Integrated Learning, Vol. 19, No. 2, pp. 193-204.

*Renganathan, S., Abdul Karim, Z. A. B. and Li, C. S. (2012), "Students' perception of industrial internship programme", Education + training, Vol. 54, No. 2/3, pp. 180-191.

*Rowe, J. W. and Mulroy, T. J. (2004), "A Qualitative Study of the Student Internship Experience", Proceedings of the ASEE Annual Conference and Exposition, Salt Lake City.

*Rulifson, G. and Bielefeldt, A. (2018), "Influence of Internships on Engineering Students' Attitudes about Socially Responsible Engineering”, IEEE Frontiers in Education Conference (FIE).

Schon, D. A. (1983). "The reflective practitioner", New York: Basic Books.

*Smith, J. M. and Lucena, J. C. (2016), "Invisible innovators: how low-income, first- generation students use their funds of knowledge to belong in engineering", Engineering Studies, Vol. 8, No. 1, pp. 1-26.

*Tillman, R. (1990), "Professional Ethical Orientation of Civil Engineering Co-op Students", Journal of Professional Issues in Engineering, Vol. 116, No. 2, pp. 175-187.

Titus, C. and Oakes, W. C. (2011), "Designing in a social context: Situating design in a human centered, social world", Proceedings of the ASEE Annual Conference and Exposition, Vancouver.

Trede, F. (2012), "Role of work-integrated learning in developing professionalism and professional identity", Asia-Pacific Journal of Cooperative Education, Vol. 13, No. 3, pp. 159-167.

Von Treuer, K., Sturre, V., Keele, S. and McLeod, J. (2011), “An integrated model for the evaluation of work placements”, Asia-Pacific Journal of Cooperative Education, Vol. 12, No. 3, pp. 196-204.

Walther, J., Sochacka, N. W. and Kellam, N. N. (2013), "Quality in Interpretive Engineering Education Research: Reflections on an Example Study”, Journal of Engineering Education, Vol. 102, No. 4, pp. 262659.

*Yin, A. (2010), "Understanding Cooperative Education and Internships: The Influence of Engineering Students Problem Solving Skills", Proceedings of the ASEE Annual Conference and Exposition, Louisville. 


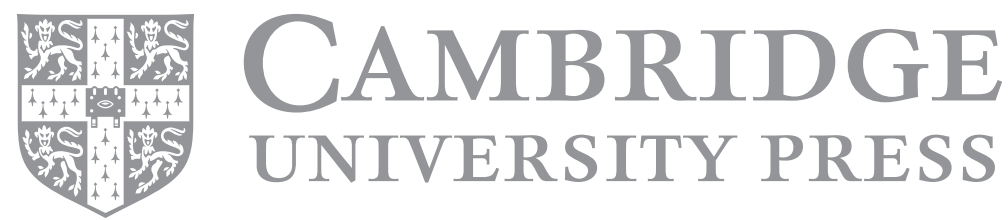

